\title{
PERANCANGAN SISTEM PENGUKUR TINGGI BADAN BERBASIS MIKROKONTROLLER MENGGUNAKAN SENSOR ULTRASONIK
}

\author{
${ }^{1)}$ Ahmad Hanafie, ${ }^{2)}$ Bowasis Umar, ${ }^{3)}$ Nurul Husnah, ${ }^{4)}$ Sukma Yunus \\ ${ }^{1)}$ Dosen Program Studi Teknik Industri Fakultas Teknik Universitas Islam Makassar \\ ${ }^{2)}$ Dosen Program Studi Teknik Informatika Fakultas Teknik Universitas Islam Makassar \\ ${ }^{3,4)}$ Mahasiswa Program Studi Teknik Informatika Fakultas Teknik Universitas Islam Makassar \\ J1.Perintis Kemerdekaan KM 9 NO 29 Kampus UIM, Tlpn 0411-588-167 \\ Email : ahmadhanafie.dty@uim-makassar.ac.id
}

\begin{abstract}
ABSTRAK
Penelitian ini bertujuan untuk merancang sebuah alat pengukur tinggi badan yang berbasis mikrokontroller menggunakan sensor ultrasonik untuk memudahkan pengguna dalam pengukuran tinggi badan.Sistem ini terdiri dari beberapa komponen elektronik seperti LCD, Mikrokontroller, Sensor Ultrasonik, dan masih banyak lagi yang dibangun menggunakan bahasa pemrograman bahasa C. Adapun metode penelitian yang digunakan dalam eksperimen ini adalah pengujian langsung alat.Hasil dari tugas akhir ini adalah sebuah alat pengukur tinggi badan berbasis mikrokontroller yang menggunakan sensor ultrasonik yang dilengkapi dengan tampilan hasil ukur tinggi badan melalui LCD. Berdasarkan hasil pembuatan, pengoperasian, dan pengujian alat, diketahui bahwa mekanisme kerja alat pengukur tinggi badan berbasis mikrokontroller menggunakan sensor ultrasonik bekerja sesuai dengan harapan dan teori yang mendukung.
\end{abstract}

Kata kunci : Mikrokontroller, Sensor Ultrasonik, LCD.

\section{PENDAHULUAN}

\subsection{Latar Belakang}

Alat ukur merupakan suatu alat yang dapat digunakan oleh manusia untuk membantu dalam proses penentuan parameter. Terdapat berbagai macam alat ukur yang telah ada saat ini. Salah satu alat ukur tersebut ialah alat ukur tinggi untuk mengukur ketinggian suatu objek. Kebanyakan alat ukur tinggi yang digunakan saat ini ialah alat ukur tinggi analog.

Pengukuran merupakan hal yang penting dalam dunia ilmu pengetahuan. Pengukuranpengukuran tersebut antara lain, pengukuran waktu dari satu kejadian ke kejadian yang lainnya, pengukuran temperatur/suhu suatu daerah, dan pengukuran kecepatan dari suatu benda dan pengukuran tinggi dari satu titik ke titik lain.Seperti alat ukur analog dan digital.

Alat ukur analog merupakan alat ukur generasi awal dan sampai saat ini masih digunakan.
Seperti mistar, jangka sorong dan meteran lipat.

Alat ukur digital adalah alat ukur yang menunjukan besaran yang diukur dalam bentuk angka. Dengan alat ukur digital, kesalahan pembacaan dihilangkan oleh penunjukan langsung dengan angka dari besaran yang diukur, dan titik desimal ditunjukan pula secara langsung untuk memudahkan pengukuran.

Alat ukur tinggi analog tingkat akurasi ukur yang di hasilkan belum terlalu efektif. Sementara pada alat ukur digital, nilai dapat langsung dibaca besarnya karena ditampilkan dalam bentuk digit angka.

Seiring dengan perkembangan komputer yang sangat pesat, alat ukur tinggi analog sudah di kembangkan menjadi alat ukur tinggi digital, karna alat ukur tinggi digital memiliki tingkat akurasi ukur yang tepat.

Salah satu teknologi yang berkembang pesat pada era saat ini adalah teknologi dibidang mikrokontroller. Dimana 
mikrokontroller dapat berfungsi sebagai pengontrol utama dalam sistem elektronik digital.

Seiring perkembangan teknologi maka manusia menggunakan alat ukur digital dengan menggunakan sensor ultrasonik. Sensor ultrasonik biasanya diaplikasikan kepada ketinggian, misalnya mengukur ketinggian gunung, lautan dan daratan. Sensor ultrasonik juga digunakan pada perangkat yang membutuhkan perhitungan jarak. Contohnya smart robot, kapal laut, kapal selam, dan lain-lain. Sehingga dengan fungsinya tersebut teknologi ini yang kami gunakan untuk merancang alat tersebut.

\subsection{Rumusan Masalah}

1. Bagaimana merancang alat ukur tinggi badan berbasis mikrokontroller menggunakan sensor ultrasonik ?

2. Bagaimana menguji hasil perancangan sistem pengukur tinggi badan berbasis mikrokontroller menggunakan sensor ultrasonik ?

\subsection{Tujuan Penelitian}

1. Untuk merancang alat ukur tinggi badan berbasis mikrokontroller dengan menggunakan sensor ultrasonik.

2. Untuk menguji hasil perancangan dengan menggunakan metode pengujian langsung.

\section{METODOLOGI PENELITIAN}

\subsection{Waktu dan Tempat Penelitian}

Waktu penelitian direncanakan dilakukan selama 3 (tiga) bulan, terhitung dari bulan Februari sampai April 2017, dengan tempat penelitian di Laboratorium Teknik Elektro Fakultas Teknik Universitas Islam Makassar beralamat di Jl. Perintis Kemerdekaan Km 9, No. 29 Makassar - Sulawesi Selatan Indonesia.

\subsection{Alat dan Bahan Penelitian}

2.2.1 Alat Penelitian
a. Obeng plus
b. Obeng minus
c. Tang potong
d. Mistar ukur
e. Solder
f. Pengisap timah
g. Laptop
h. Kabel downloader
i. Katter

\subsubsection{Bahan Penelitian}
a. Papan PCB
b. Mikrokontroller arduino uno
c. Sensor ultrasonik
d. Besi
e. kabel jamper
f. LCD $16 \times 2$
g. Baterai 9 volt
h.Timah
i. Box
j. Lem / pelekat
k. Tripot
1. Soulder
m. Jack male dan female

\subsection{Analisis Perancangan}

Pada penelitian ini yaitu dengan menggunakan sensosr ultrasonik yang mengirim cahaya ke suatu objek lalu di pantulkan kembali ke sensor. setelah di terima sensor akan memberi informasi kepada microkontroler arduino uno untuk di proses dan menghasilkan ukuran tinggi badan ke LCD 16X2 tersebut.

\subsection{Prosedur Kerja}

Prosedur kerja bertujuan untuk memindahkan proses perancangan ke dalam bentuk yang sesuai berupa alat yang siap untuk di gunakan. Adapun prosedur kerja adalah:

1. Menentukan alat dan bahan

2. Desain sistem

3. Merancang alat

4. Ujicoba alat

5. Validasi

\subsection{Metode Penelitian}

Data penelitian yang di perlukan dalam penyusunan laporan tugas akhir di peroleh melalui metode studi pustaka, studi laboraturium dan studi literatur.

1. Studi pustaka

Data penelitian di peroleh dari sumber pustaka yang meliputi buku, majalah atau arsip mengenai topik yang di bahas dalam 
penelitian. Data penelitian juga di peroleh dari internet. Buku yang di gunakan berupa buku konsep.

2. Studi Literatur

Studi literatur di lakukan dengan guna memperoleh teori-teori pendukung serta kemungkinan asumsi yang di gunakan dan berperan sebagai referensi dalam mencari pendekatan secara teoritis dari permasalahan yang di angkat yang bersumber antara lain pada buku atau bahan pustaka, karya ilmiah, dan website.

\subsection{Flowchart Penelitian}

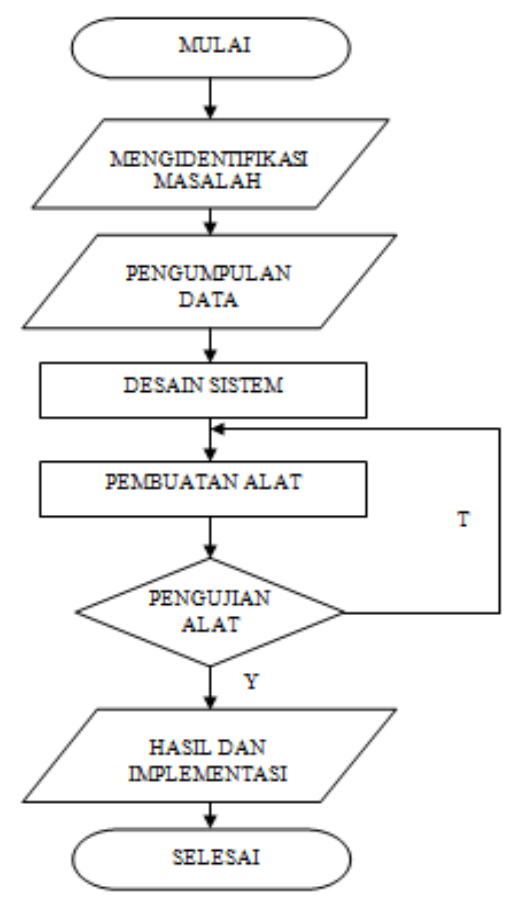

Gambar 2.1 Flowchart Penelitian

\section{ANALISA DAN PEMBAHASAN}

\subsection{Flowchart Perancangan}

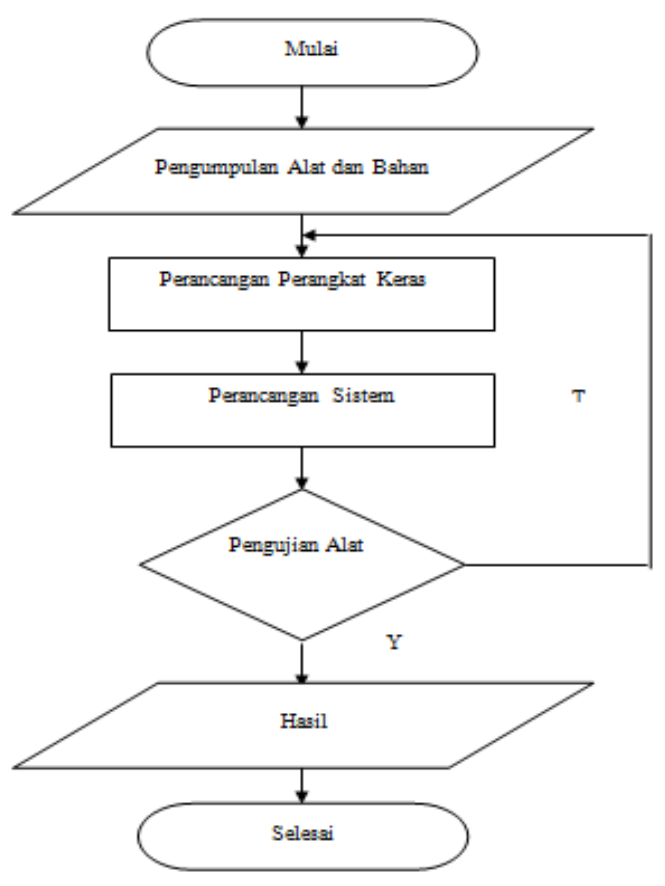

Gambar 3.1 Flowchart Perancangan

\subsection{Perancangan Perangkat Keras}

Adapun perancangan keras pertama yaitu menyiapkan indomaxi hollow kotak dengan tipe 40x40x0.30 dengan panjang $4 \mathrm{~m}$, yang kemudian dibagi menjadi lima bagian :

1. Kuda-kuda tengah berukuran $40 \mathrm{~cm}$.

2. Kuda-kuda kanan berukuran $50 \mathrm{~cm}$.

3. Kuda-kuda kiri berukuran $50 \mathrm{~cm}$.

4. Tiang berukuran $200 \mathrm{~cm}$.

5. Kuda-kuda dudukan sensor berukuran $27,7 \mathrm{~cm}$.

Setelah dipotong menjadi lima bagian dengan ukurannya masing-masing menggunakan mesin gurinda, Kemudian potongan-potongan indomaxi hollow kotak dihubungkan untuk membentuk suatu rangkaian dengan menggunakan skrup dan mesin bor. Dan box dengan berukuran 16x12.5 dipasang pada tiang dengan menggunakan skrup dan mesin bor.

Perancangan perangkat keras selanjutnya yaitu menghubungkan pin-pin arduino dengan sensor ultrasonik dan Lcd. Adapun pin-pin untuk menghubungkan Arduino, Sensor ultrasonik dan Lcd yaitu pin-pin yang terhubung adalah pin 12 sebagai input lcd pin RS, pin 11 sebagai input lcd pin Enable, pin 5 sebagai input lcd pin D4, pin 4 sebagai input lcd pin D5, pin 3 sebagai input lcd pin D6, pin 
2 sebagai input lcd pin D7, grounding sebagai input lcd pin $\mathrm{R} / \mathrm{W}$, grounding sebagai input lcd pin VSS, 5 Volt sebagai input lcd pin VCC dan grounding yang langsung diambil pada power adaptor yang terhubung dengan modul arduino, dan pin-pin yang terhubung adalah GND sensor terhubung pada papan PCB (-), Echo sensor terhubung pada pin 10 arduino, Trigger sensor terhubung pada pin 9 arduino,dan VCC sensor terhubung pada papan PCB (+).
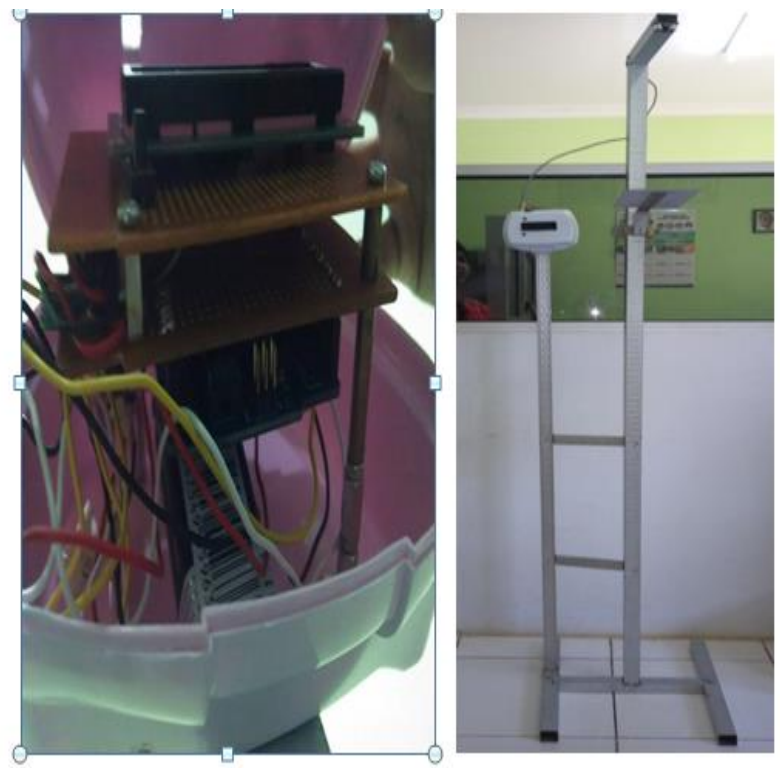

Gambar 3.2 Perancangan Perangkat Keras

\subsection{Perancangan Sistem}

\subsubsection{Flowchart Sistem}

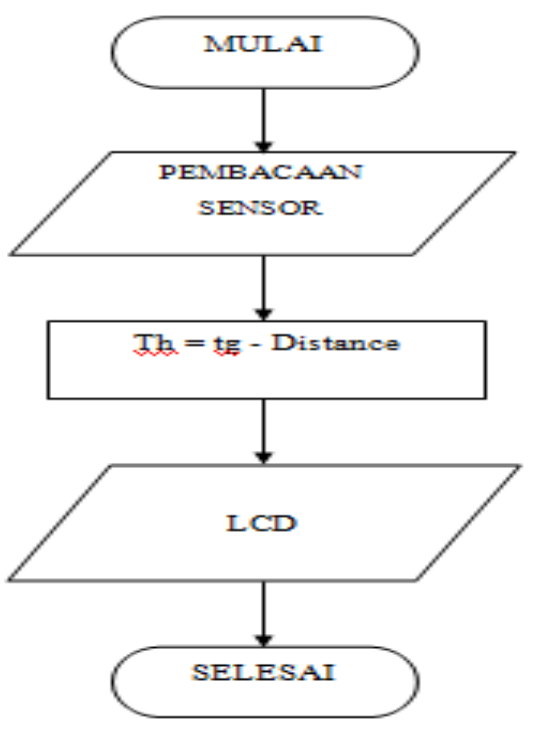

Gambar 3.3 Flowchart Sistem

\subsubsection{Perancangan Perangkat Lunak} untuk membuat library arduino dapat menggunakan software dibawah ini :

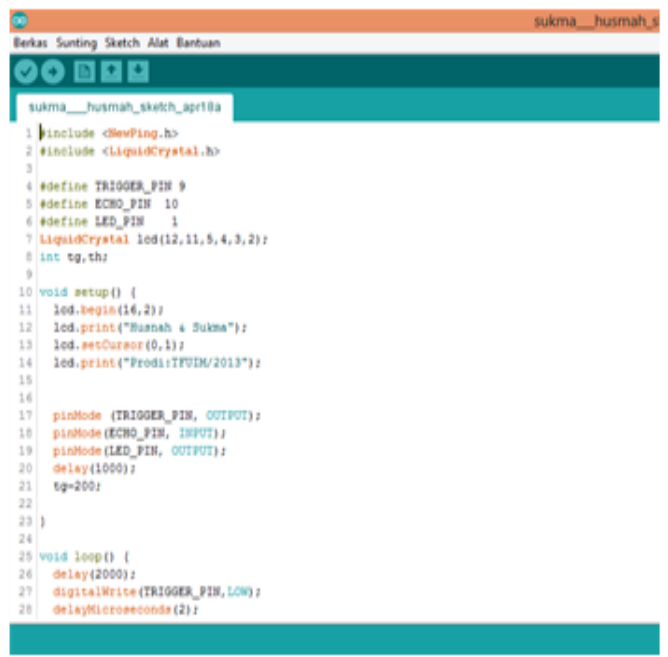

Gambar 3.4 Tampilan Software Arduino

\subsection{Pengujian Alat}

Setelah melakukan perancangan perangkat keras dan lunak maka langkah selanjutnya adalah melakukan uji coba alat seperti gambar dibawah ini
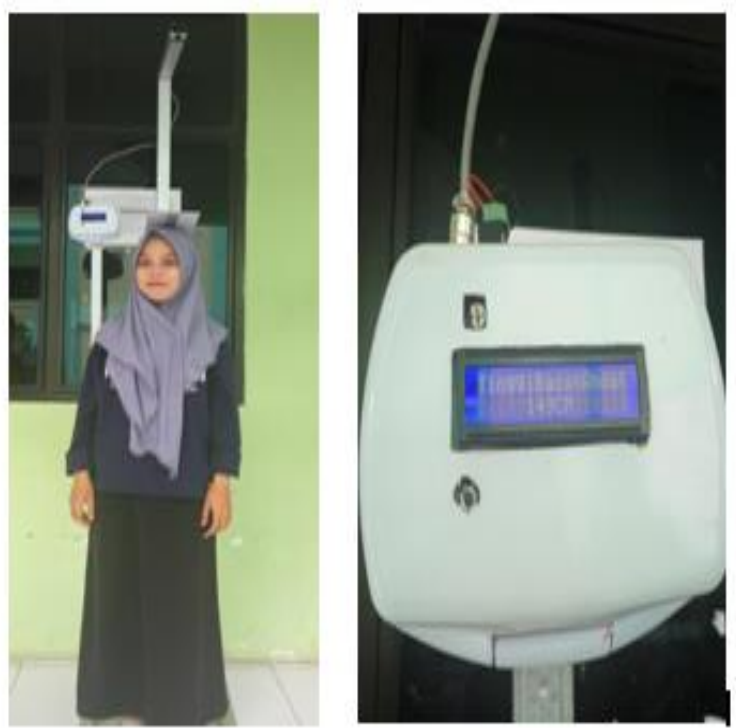

Gambar 3.5 Pengujian Alat 


\subsection{Gambaran Umum Sistem}

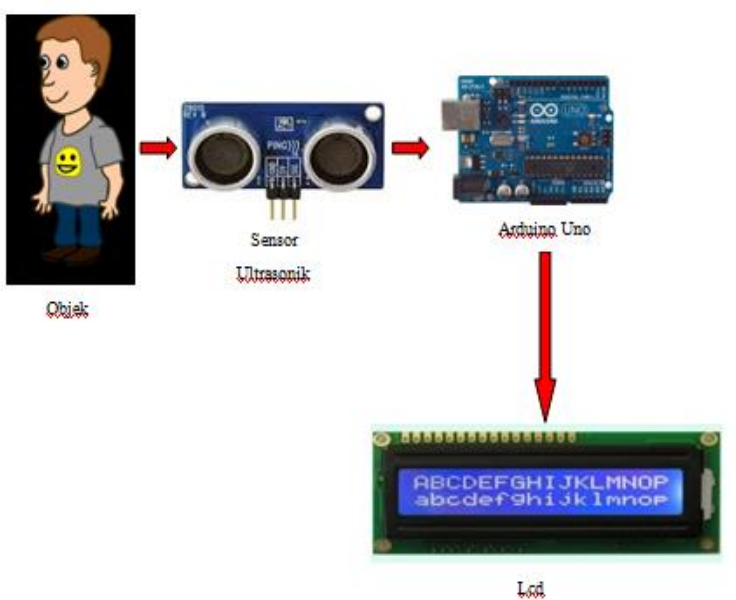

Gambar 3.5 Gambaran Umum Sistem

\section{PENUTUP}

\subsection{Kesimpulan}

Dari hasil perancangan serta pembuatan alat pengukur tinggi badan menggunakan sensor ultrasonik berbasis mikrokontroller arduino uno ini dapat disimpulkan bahwa :

1. Perancangan dengan menggunakan sensor ultrasonik menggunakan mikrokontroller arduino uno pada alat pengukur tinggi badan berhasil digunakan.

2. Dari hasil pengujian yang kami lakukan didapatkan bahwa penggunaan alat ini berjalan dengan baik margin atau selisih kesalahan yang kecil.

\subsection{Saran}

Untuk kedepannya, kami berharap dalam perancangan sistem pengukur tinggi badan berbasis mikrokontroller menggunakan sensor ultrasonik supaya mampu di buat dengan rancangan yang lebih sempurna dan lebih baik lagi.

\section{DAFTAR PUSTAKA}

Al-Bahra Bin ladjamudin. 2005, "Analisis dan Desain Sistem Informasi”.

Tangerang : Penerbit Graha ilmu.
Budiharto,W.2007, “Belajar Sendiri 12 Proyek Mikrokontroler Untuk Pemula". Jakarta : Penerbit Elex Media Komputindo

Fatta,Al Hanif. 2007. "Analisis dan Perancangan Sistem Informasi". Yogyakarta : Penerbit Andi

Jogiyanto H.M. 2005. “Analisis dan Desain Sistem Informasi, Pendekatan Terstruktur Teori dan Praktek Aplikasi Bisnis". Yogyakarta : Penerbit Andi.

Kadir, Abdul. 2005. "Pengenalan Sistem Informasi". Yogyakarta : Penerbit Andi.

Kandar, Aris. "Perancangan Penampil Teks Berbasis Mikrokontroler PIC16F877A." USU : Medan, 2010.

Kusrini, dkk. 2007, "Tuntunan Praktis Membangun Sistem Informasi Akuntansi dengan Visual Basic dan Microsoft SQL Server". Yogyakarta : Penerbit Andi.

Malik,Juwana. 2009, "Aneka Proyek Mikrokontroller PIC16F84/A". Jakarta : Penerbit Elex Media Komputindo.

Murdick, Ross. 1993. "Perancangan dan Pembangunan Sistem Informasi". Yogyakarta : Penerbit Andi

Sudjadi. 2005, "Teori dan Aplikasi Mikrokontroler". Yogyakarta : Penerbit Graha ilmu.

Syamsul Bahri Wagola,Aljid Tirto Pangestu, " Perancangan Sistem Pengontrolan Lampu Perkantoran Menggunakan Arduino Uno Melalui Bluetooth". Makassar

Wahyuddin. 2007, "Belajar Mudah Mikrokontroller AT89S52 dengan Basic Menggunakan Bascom-805”. Yogyakarta : Penerbit Andi

http://arduinotutorials.blogspot.com/2013/12/caramemprogram-arduino.html

http://hedisasrawan.blogspot.com/2014/01/25 -pengertian-sistem-menurut-para-ahli.html https://id.wikipedia.org/wiki/Sensor) http://www.arti-definisi.com/Ultrasonik https://id.wikipedia.org/wiki/Ultrasonik http://mrizalfahmi31.blogspot.co.id/2015/03/a lat-ukur-besaran-besaran-listrik.html http://henii-241.blogspot.co.id/2011/07/alatukur-digital.html 